\title{
VERIFICATION OF OPERATION MODES OF DESIGNED LLC RESONANT CONVERTER
}

This paper describes the design of the LLC resonant converter, which is done by means of fundamental harmonic approximation (FHA). Output power of proposed converter is $1 \mathrm{~kW}$ with output voltage $48 \mathrm{~V}$ at switching frequency of $500 \mathrm{kHz}$. Performance of converter at different operational conditions was verified through simulation analysis by utilization of OrCAD PSpice software. The simulation results of multiple parametrical experiments were obtained and consequently evaluated into graphical interpretation of efficiency of proposed converter.

\section{Introduction}

LLC resonant converter is multi-resonant converter and is characterized by its unique DC - gain characteristic, which has two resonant frequencies $\left(f_{0}\right.$ and $\left.f_{p}\right)$. This converter has several advantages compared to standard serial LC resonant topology. One of them is possibility of stable regulation of output voltage in a wide range of input voltages together with the change of output power from $1 \%$ to $100 \%$. The next advantage is achievement of ZVS switching mode during various operational modes. LLC resonant converter is composed of three functional parts (Fig. 1). It deals with pulse generator, resonant circuit with high-frequency transformer and rectifier with capacitive filter.

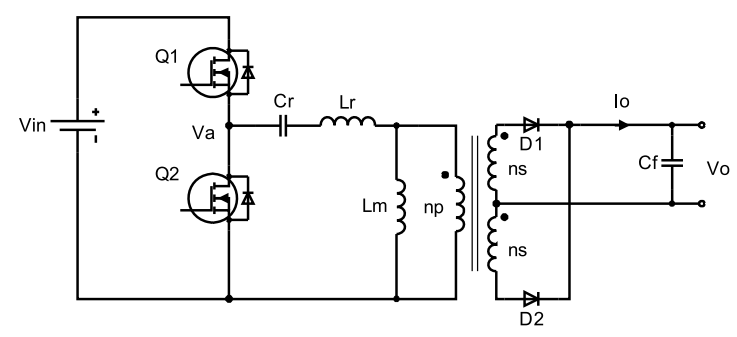

Fig. 1 Principal schematic of LLC converter

From the DC - gain characteristic of LLC converter it could be seen that, when the input voltage is constant and the converter operates at the switching frequency near to resonant frequency $f_{0}$, the gain of converter is independent on the variations of load, which results in small regulation range. On the other hand at different operating conditions, the operating point varies between lower and upper resonant frequency in relation to power loading and input voltage. There exist restrictions which are determining boundaries of reliable function and are described more in detail in
[1]. Mathematical interpretation of gain characteristic is described by next equation:

$$
M=\frac{2 n V_{0}}{V_{m}}=\left|\frac{\left(\frac{\omega^{2}}{\omega_{0}^{2}}\right) \cdot \sqrt{m \cdot(m-1)}}{\left(\frac{\omega^{2}}{\omega_{p}^{2}}-1\right)+j \cdot\left(\frac{\omega}{\omega_{0}}\right) \cdot\left(\frac{\omega^{2}}{\omega_{0}^{2}}-1\right) \cdot(m-1) Q}\right|
$$

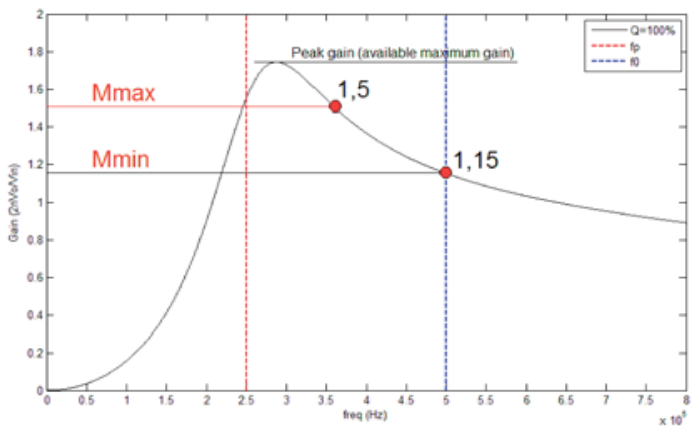

Fig. 2 DC - gain characteristics of proposed LLC resonant converter

\section{Operation modes}

Operation of LLC converter in different operational modes is described by DC gain characteristic, which should be divided into ZVS and/or ZCS region. ZVS region in dependency on the switching frequency can be further divided into:

- region with switching frequency equal to resonant $\left(f_{s}=f_{0}\right)$

- region with switching frequency higher than resonant $\left(f_{s}>f_{0}\right)$

- region with switching frequency lower than resonant $\left(f_{s}<f_{0}\right)$

\footnotetext{
* Pavol Spanik, Jozef Kandrac, Michal Frivaldsky, Peter Drgona

Department of Mechatronics and Electronics, Faculty of Electrical Engineering, University of Zilina, Slovakia, E-mail: pavol.spanik@fel.uniza.sk
} 


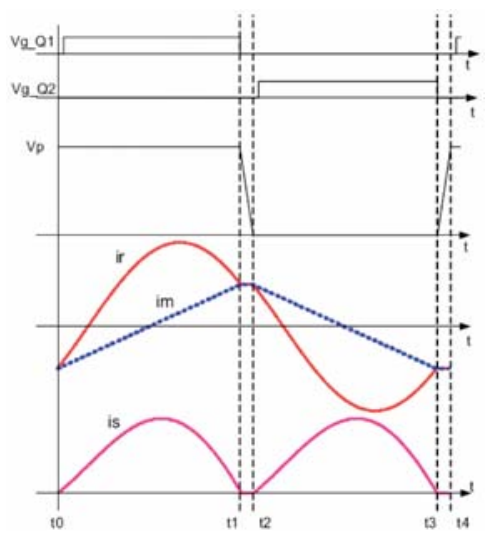

a)

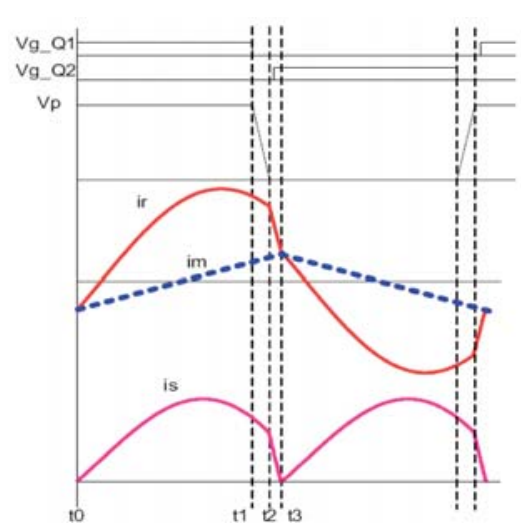

b)

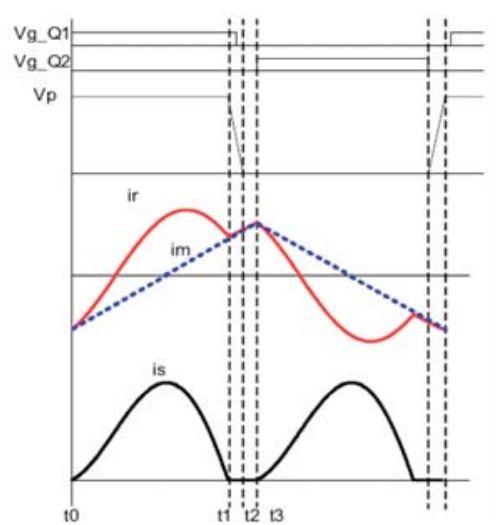

c)

Fig. 3 Waveforms of currents and voltages of LLC converter at different operating conditions a) $\left.\left.f_{s}=f_{0}, b\right) f_{s}>f_{0}, c\right) f_{s}\left\langle f_{0}\right.$

According to the operational modes of resonant converters the operation of LLC resonant converter is rather difficult. The principal waveforms of transformer and output diode during each operating mode are shown in Fig. 3.

The impedance of series resonant circuit at the resonant frequency is equal to zero. Therefore the reflected output voltage is equal to the input voltage, which is described by the unity of voltage gain thus the circuit then operates optimally. LLC resonant converter can achieve gain greater, less or equal to 1 . If the switching frequency is less than the resonant frequency, magnetization inductance is involved into the resonance of the circuit so the converter can deliver higher gain.

\section{Design parameters of the main circuit}

Target of the design is to determine the active and passive elements of the proposed converter. Main electrical parameters are:

$$
\begin{aligned}
& f_{0}=500 \mathrm{kHz}, P_{O}=1 \mathrm{~kW}, U_{O}=48 \mathrm{~V}, \\
& I_{O}=21 \mathrm{~A}, \text { efficiency }=0.96
\end{aligned}
$$

\section{A. Estimated efficiency}

For the low voltage applications, the efficiency varies from 0.88 to 0.92 . For the high voltage applications, the efficiency varies from 0.92 to 0.96 . In our case, we expect efficiency with a value of 0.96 . Input power is then calculated as:

$$
P_{I N}=\frac{P_{o}}{E_{f f}}=\frac{U_{0} I_{0}}{E_{f f}}=\frac{48.21}{0.96}=\frac{1008}{0.96}=1050 \mathrm{~W}
$$

\section{B. Determination of the maximum and minimum input voltage}

The advantage of LLC converter is its ability to work in a wide range of input voltages. In our proposal we considered the following values of input voltages:

$$
\begin{array}{ll}
\text { Minimal input voltage } & V_{\text {inmin }}=325 \mathrm{~V} \\
\text { Maximal input voltage } & V_{\text {inmax }}=425 \mathrm{~V}
\end{array}
$$

Regulation is based on frequency modulation, through which the voltage gain can be changed. The main parameter that determines the value of voltage gain, and thus the range of frequency control, is ratio (" $m$ ") of the magnetizing and resonant inductance.

\section{Determination of maximum and minimum voltage gains}

When converter operates at nominal input voltage $V_{I N}=425 \mathrm{~V}$ then the switching frequency is determined to be $f_{0}=500 \mathrm{kHz}$. Also at the resonant frequency the voltage gain is determined from the value of inductance ratio $\left(m=L_{m} / L_{r}\right)$. During determination, there exist some design tradeoffs. For example, the higher value of $m$ will results in the higher value of conduction losses, the higher regulation range and in the higher volume of the transformer core. On the other hand, the lower value of $m$ deteriorates transformer coupling and reduces efficiency (Figs 4-6).

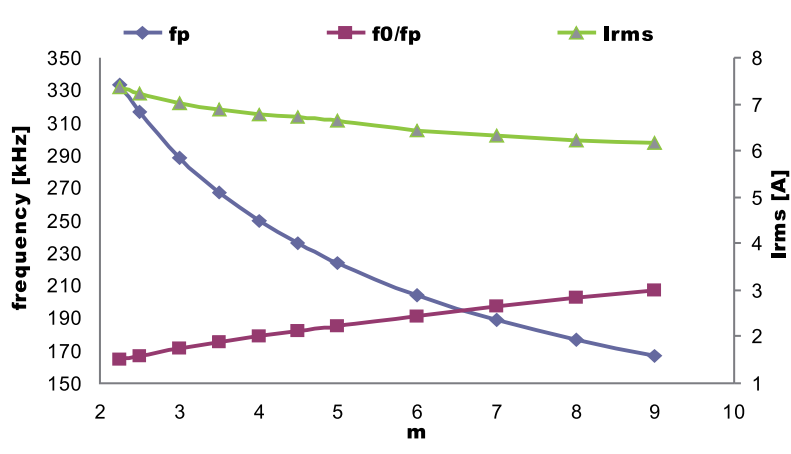

Fig. 4 Dependency of parallel resonant frequency $\left(f_{p}\right)$, ratio of $f_{0} / f_{p}$ and $I_{R M S}$ on the value of $m$

Selection of $m$ value: $m=4$ 


$$
\begin{aligned}
& M_{\min }=\sqrt{\frac{m}{m-1}}=\sqrt{\frac{4}{4-1}}=1.15 \\
& M_{\max }=\frac{V_{I N \text { max }}}{V_{I N \text { min }}} M_{\min }=\frac{425}{325} 1.15=1.5
\end{aligned}
$$

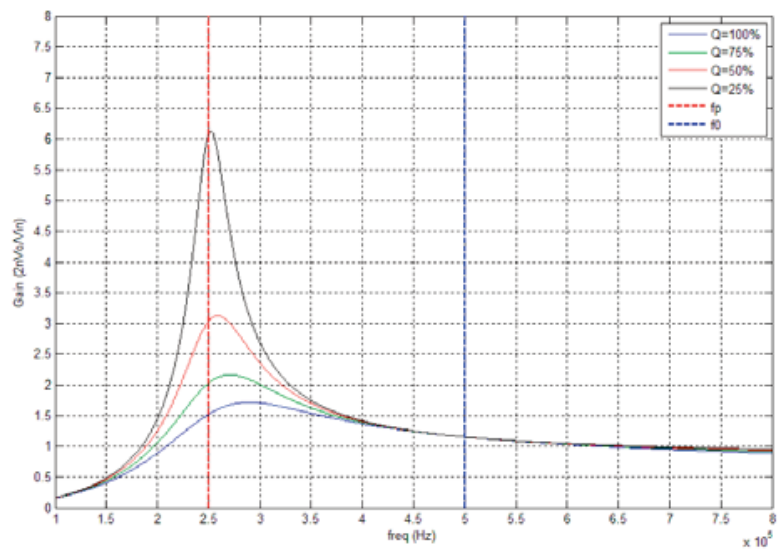

Fig. 5 DC gain characteristic of proposed LLC resonant converter for various values of output power $(m=4)$

For selected value of $m=4$, the regulation range is $250 \mathrm{kHz}$, whereby the lower resonant frequency $f_{p}$ is equal to $250 \mathrm{kHz}$ and upper resonant frequency $f_{0}$ is equal to $500 \mathrm{kHz}$.

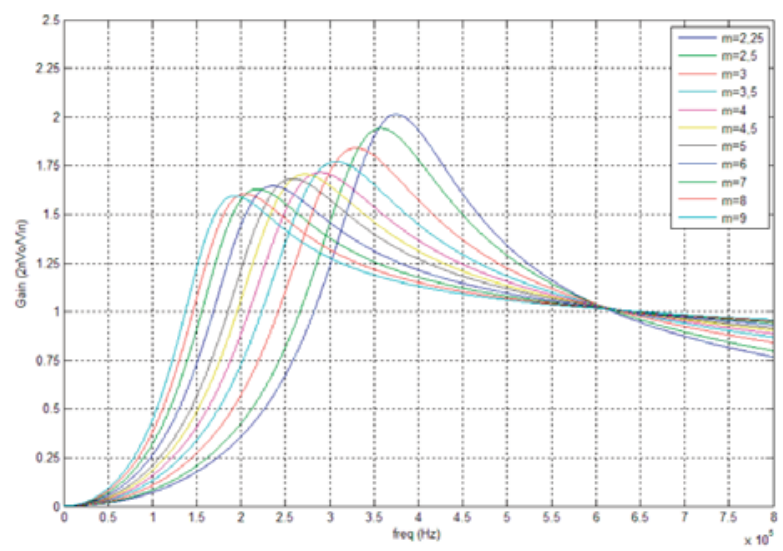

Fig. 6 DC - gain characteristics for different values of $m$ (2.25 to 9) and for $100 \%$ of output power

\section{Determinations of transformer turns ratio}

From the value of minimal gain, we can calculate the ratio of transformer ration using the following formula:

$$
\begin{aligned}
& n=\frac{N_{P}}{N_{S}}=\frac{V_{I N \max }}{2\left(U_{o}+U_{F}\right)} M_{\min }= \\
& =\frac{425}{2(48+0.96)} 1.15=4.99 \cong 5
\end{aligned}
$$

where $U_{o}$ is output voltage of converter, and $U_{f}$ is voltage drop of the output diodes.

\section{E. Determination of equivalent load resistance}

From the value of transformer ratio we will calculate reflected output load resistance to the primary side:

$$
R_{A C}=\frac{8 n^{2}}{\pi^{2}} \frac{U_{O}^{2}}{P_{O}}=\frac{8.5^{2}}{\pi^{2}} \frac{48^{2}}{1008}=46.32 \Omega
$$

\section{F. Design of resonant network}

To ensure the stable operation of ZVS and sufficient gain it is necessary to determine the correct value of quality factor $Q$. For this purpose it is necessary to consider margin of voltage gain from $10 \sim 20 \%$ of $M_{\max }$. In this design the value of $15 \%$ of $M_{\max }$ is being considered.

$$
M_{P E A K}=1.15 \cdot M_{M A X}=1.15 \cdot 1.5=1.725
$$

For $m=4$ and $M_{P E A K}=1.725$ and from Fig. 7 the value of quality factor is $Q=0.37$.

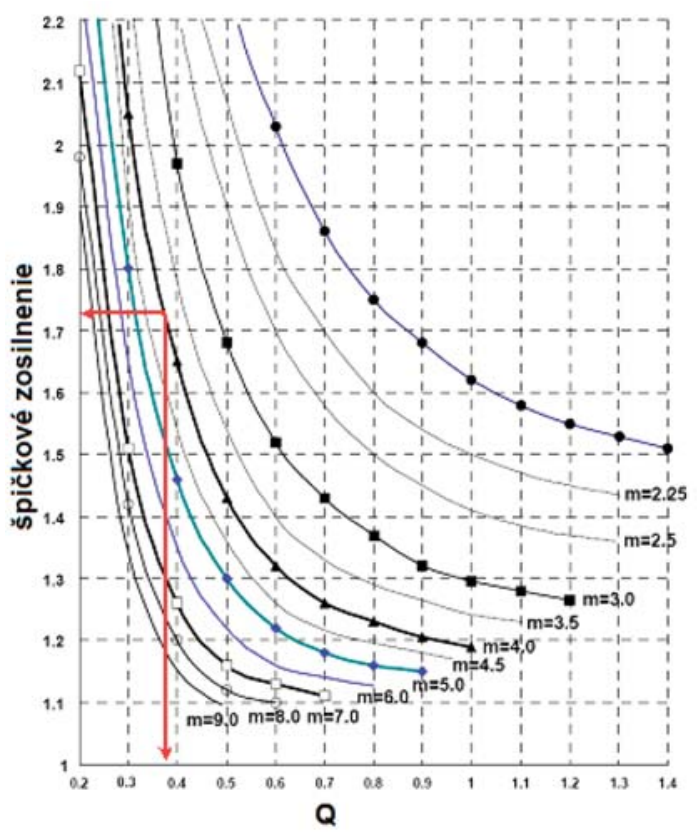

Fig. 7 Peak gain (attainable maximum gain) vs. $Q$ for different $m$ values 
After determination of required quantities, we can calculate parameters of a resonant tank using the following formulas:

$$
\begin{aligned}
& C_{r}=\frac{1}{2 \pi \cdot Q \cdot f_{0} \cdot R_{A C}}= \\
& =\frac{1}{2 \pi \cdot 0.37 \cdot 500 \cdot 10^{3} \cdot 46.32}=18.57 \mathrm{nF} \\
& L_{r}=\frac{1}{\left(2 \pi \cdot f_{0}\right)^{2} \cdot C_{r}}= \\
& =\frac{1}{\left(2 \pi \cdot 500 \cdot 10^{3}\right)^{2} \cdot 18.57 \cdot 10^{-9}}=5.45 \mu \mathrm{H}
\end{aligned}
$$

\section{Simulation analysis of the operational modes of proposed LLC resonant converter}

Operational modes of LLC resonant converter was verified in OrCAD PSpice simulation software. Simulation model of the main circuit of proposed converter is shown in Fig. 8.

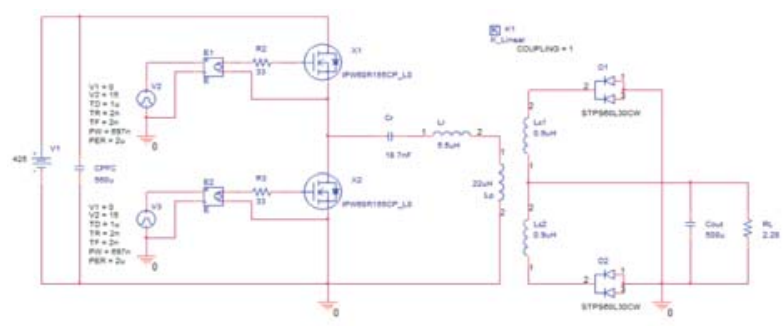

Fig. 8 Simulation model of main circuit of proposed LLC converter
As switching transistors the CoolMOS types from fy Infineon (IPW60R165CP) are being used. Rectifiers are low voltage-drop Schottky rectifier diodes from STMicroelectronics.

Fig. 9 shows the waveforms of voltages and currents on the primary side of transformer, and time waveforms of current of output rectifiers, during simulation experiment, when the switching frequency $f_{s}=f_{0}=500 \mathrm{kHz}$. This is a simulation experiment when the performance of LLC converter is expected to be optimal, since the impedance of a series resonant circuit is zero. Input voltage is clamped on the magnetizing inductance, and the voltage gain at resonant frequency is almost equal to 1 .

Fig. 10 shows the time waveforms of voltages and currents of the same elements as in the previous experiment, but the switching frequency $f_{s}>f_{0}$ and $f_{s}=630 \mathrm{kHz}$. Current through resonant circuit is slightly deformed, as well as the current of output rectifier diodes, which is caused due to discharge process of the internal capacitances of switching transistors and its consecutive turn on.

Fig. 11 shows the same situation as in previous cases, but these results were obtained from simulation experiment during which switching frequency $f_{s}<f_{0}$ and $f_{s}=360 \mathrm{kHz}$. Non-sinusoidal shape of the currents is caused due to transfer of stored energy from the magnetizing inductance into the resonant circuit thus converter is then able to increase output gain and, therefore, output voltage. In next simulation analysis, proposed converter was subjected to experiment during which output power was changed. We made 4 different experiments whereby output power was $1 \mathrm{~kW}$ and $252 \mathrm{~W}$, at input voltage of $425 \mathrm{~V}$ and $325 \mathrm{~V}$.

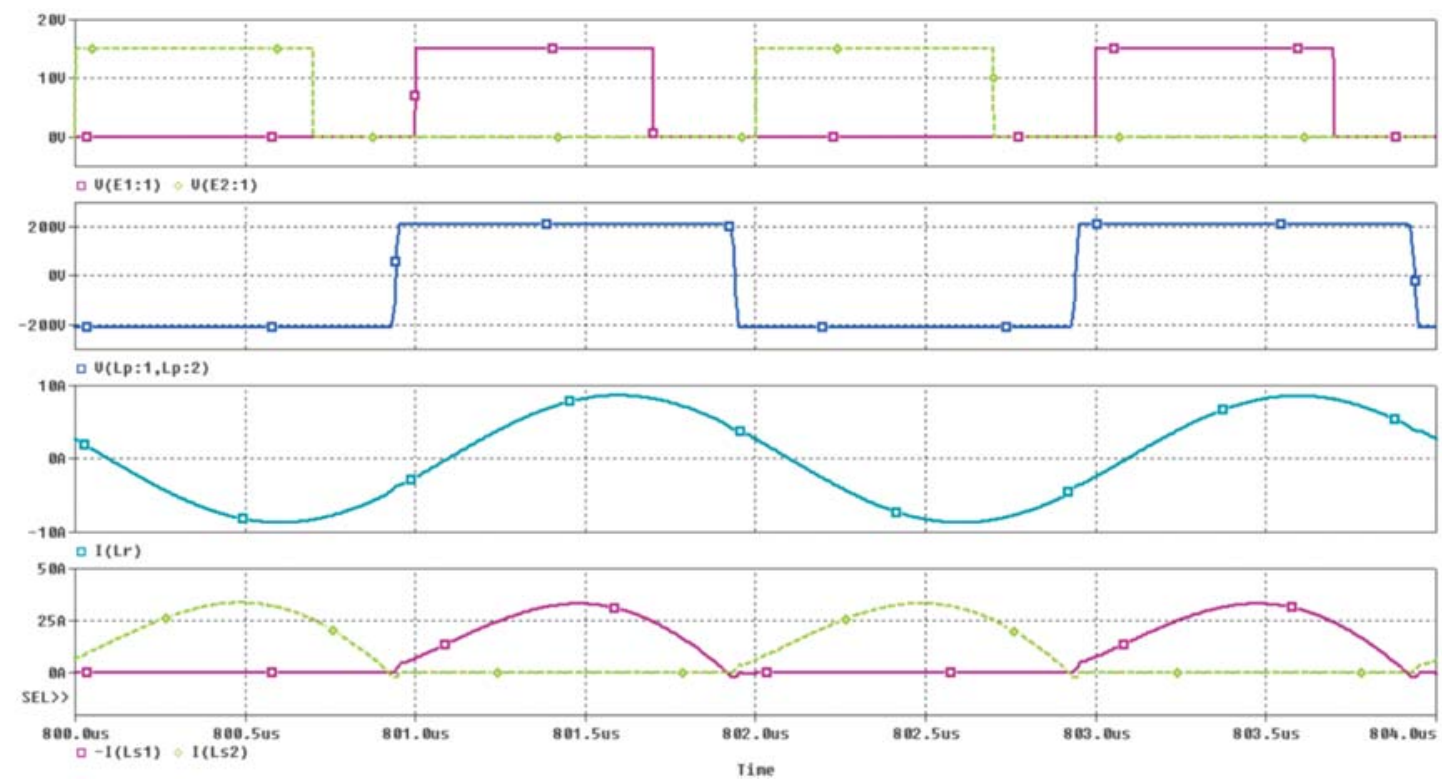

Fig. 9 Time waveforms during the simulation experiment at $f_{s}=f_{0}$ (from top - driving signals of transistors X1, X2, voltage on the primary side of transformer, current on the primary side of transformer, currents of the output diodes D1, D2) 

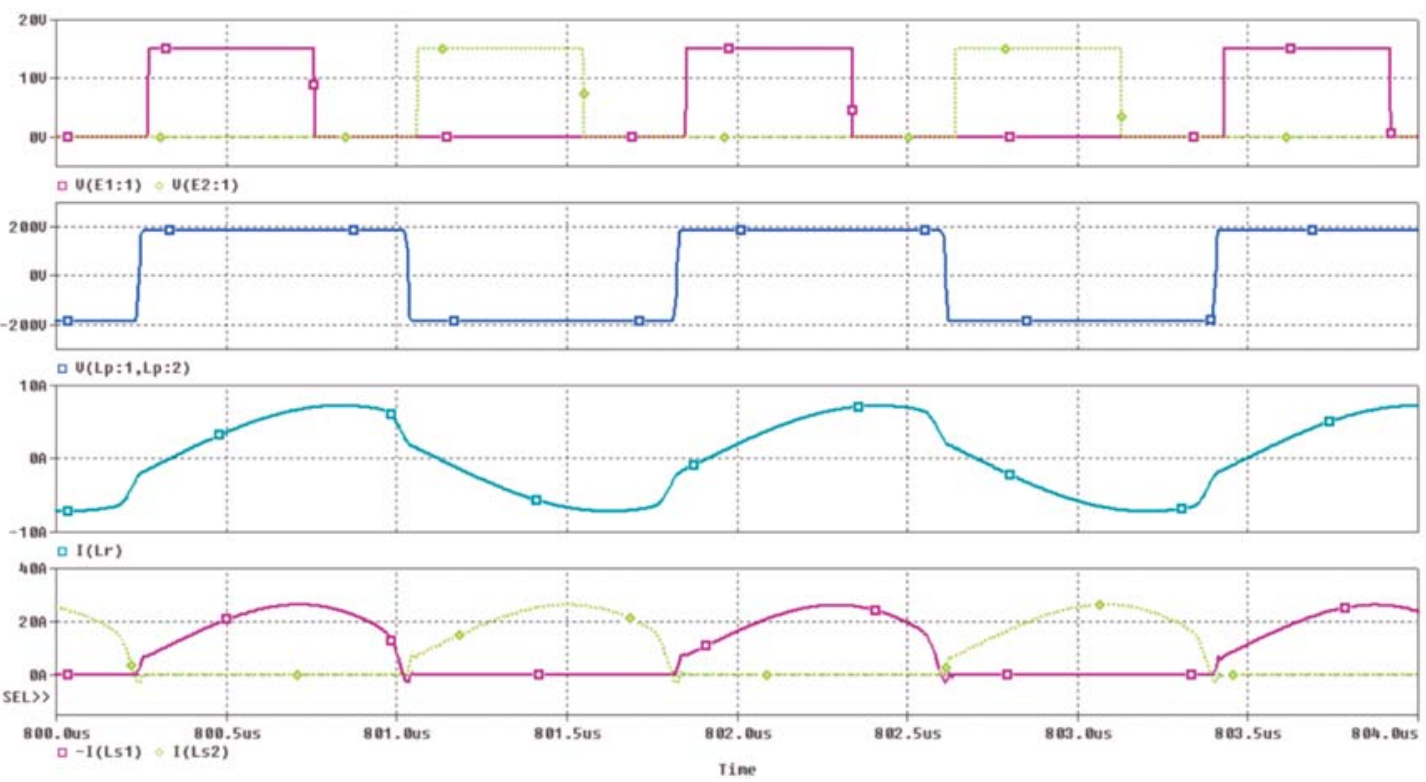

Fig. 10 Time waveforms during the simulation experiment at $f_{s}>f_{0}$ (from top - driving signals of transistors X1, X2, voltage on the primary side of transformer, current on the primary side of transformer, currents of the output diodes D1, D2)
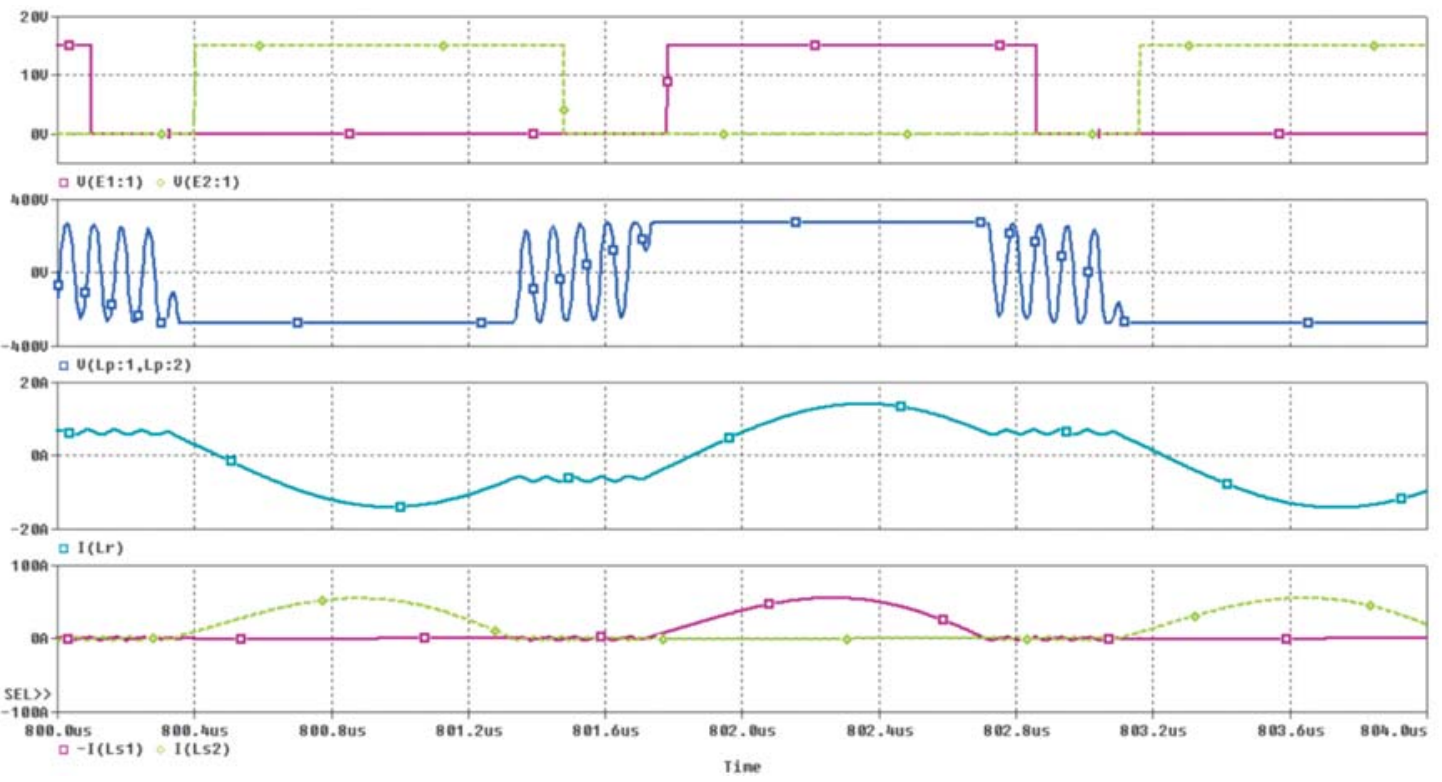

Fig. 11 Time waveforms during the simulation experiment at $f_{s}<f_{0}$ (from top - driving signals of transistors X1, X2, voltage on the primary side of transformer, current on the primary side of transformer, currents of the output diodes D1, D2)

Fig. 12 represents results from the simulation experiment, when LLC resonant converter operates at full load $\left(P_{\text {OUT }}=1008 \mathrm{~W}\right)$ when input voltage $U_{I N}=425 \mathrm{~V}$. In this mode, transistors are operating with ZVS conditions and output diodes with character of ZCS switching. The unwanted effect of reverse recovery was eliminated by utilization of Schottky rectifier diodes. Fig. 13 shows the simulation experiment at $25 \%$ of load at the input voltage $U_{I N}=$ $=425 \mathrm{~V}$. The picture shows that even at the reduced output power the switching transistors are maintaining excellent operating char- acteristics of the ZVS mode. In the case of output diodes the ZCS switching character is also still achieved.

Fig. 14 shows the simulation experiment, when LLC resonant converter operates at minimal supply voltage $U_{I N}=325 \mathrm{~V}$ and at full load condition. Simulation experiment confirmed proper design of converter. Transistor's current has sinusoidal shape until magnetizing inductance became participating in resonance with other circuit parameters. Output diodes are operating in discontinuous 


\section{COMMNICOIIONS}
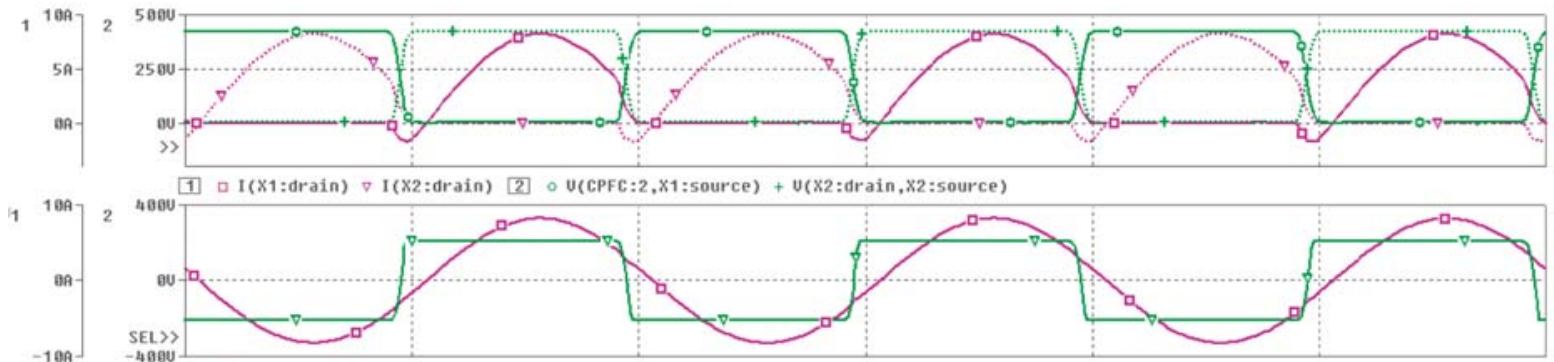

SEL

[1] $\square \mathrm{I}(\mathrm{LP})$ 2] $\nabla \mathrm{U}(\mathrm{LP}: 1,0)$

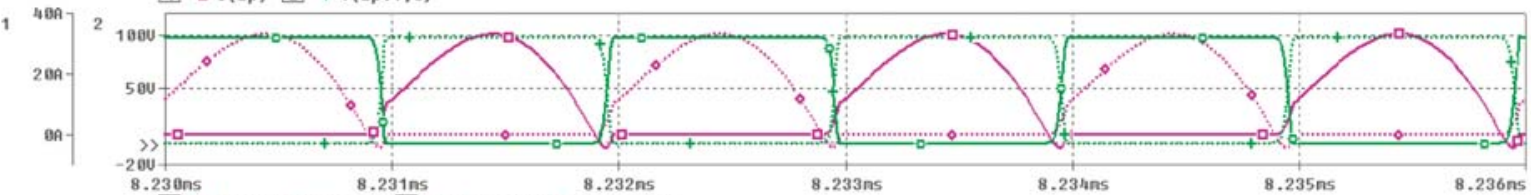

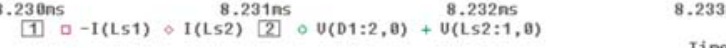

Fig. 12 Time waveforms of voltages and currents during the simulation experiment: $U_{I N}=425 \mathrm{~V}, P_{\text {oUT }}=1008 \mathrm{~W}$ (from top - transistor X1a X2, transformer primary side, output diode D1 and D2)

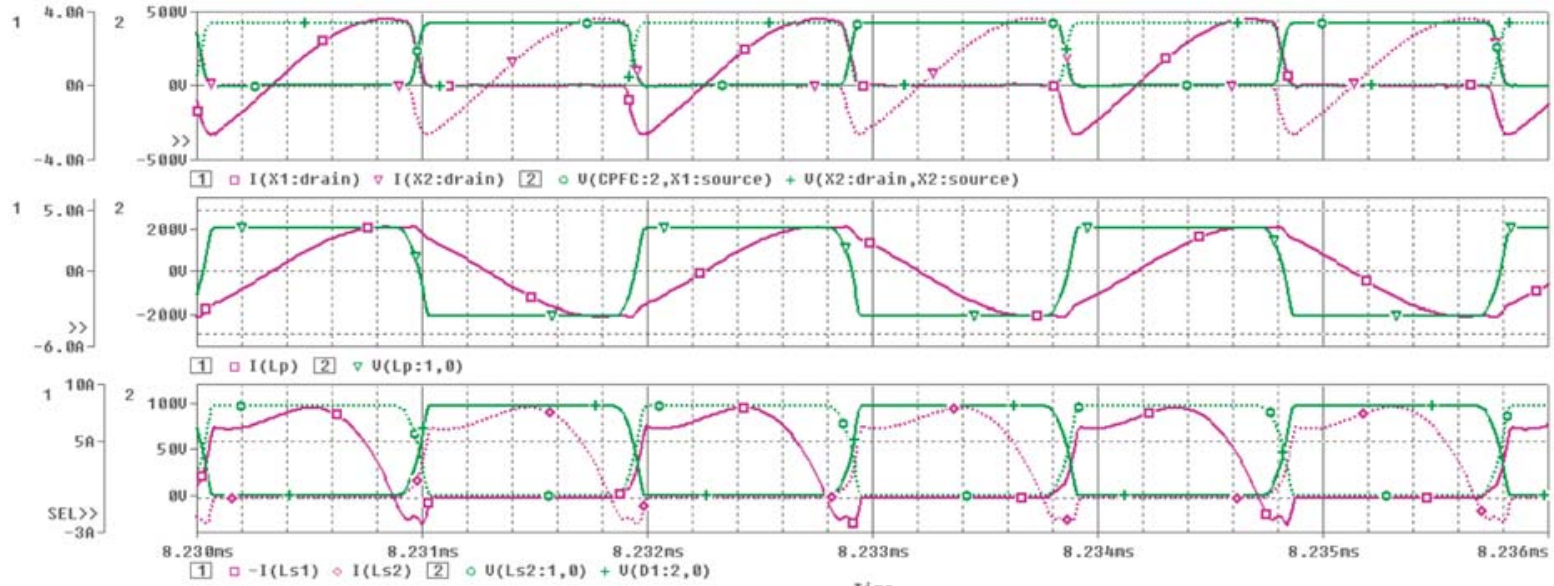

Fig. 13 Time waveforms of voltages and currents during the simulation experiment: $U_{I N}=425 \mathrm{~V}, P_{\text {OUT }}=252 \mathrm{~W}$ (from top - transistor X1a X2, transformer primary side, output diode D1 and D2)

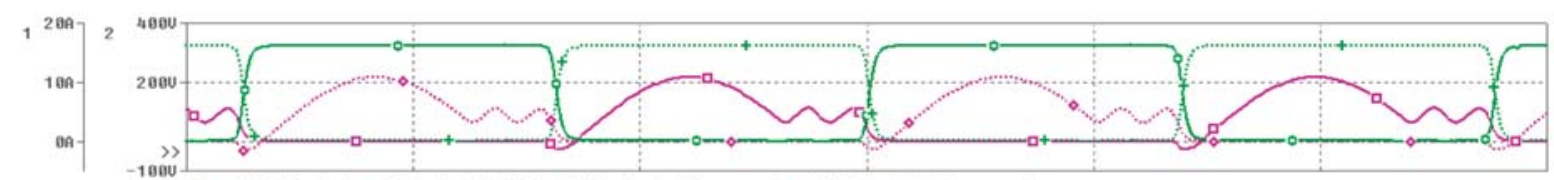

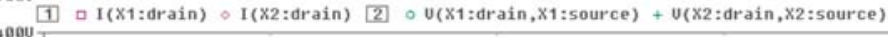

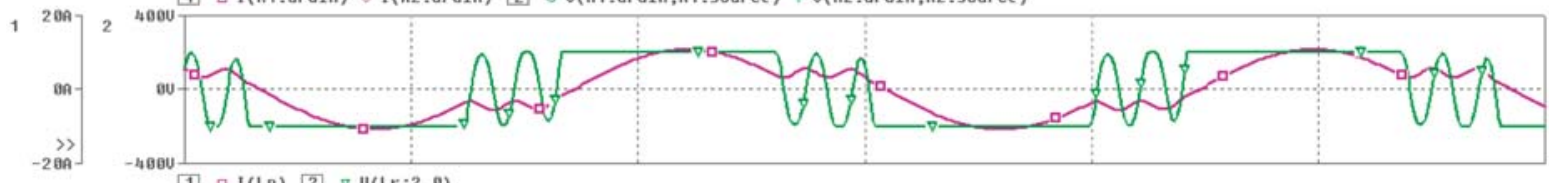

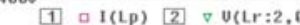

$\left.\begin{array}{c}15 \mathrm{~A} \\ 25 \mathrm{~A} \\ \mathrm{SEL} \\ -5 \mathrm{~A}\end{array}\right]$

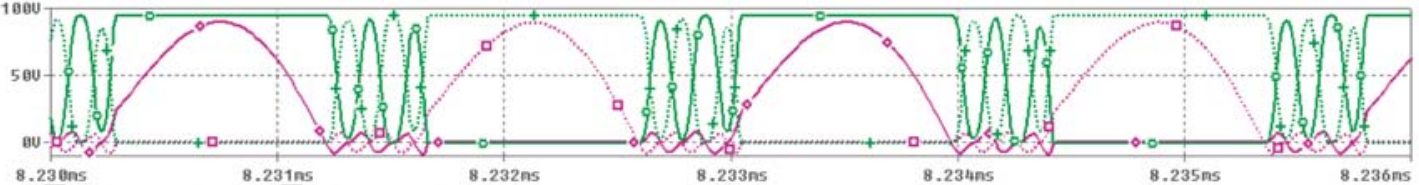

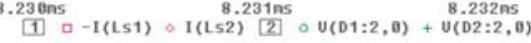

Tine

Fig. 14 Time waveforms of voltages and currents during the simulation experiment: $U_{I N}=325 \mathrm{~V}, P_{\text {OUT }}=1008 \mathrm{~W}$

(from top - transistor X1 X X2, transformer primary side, output diode D1 and D2) 


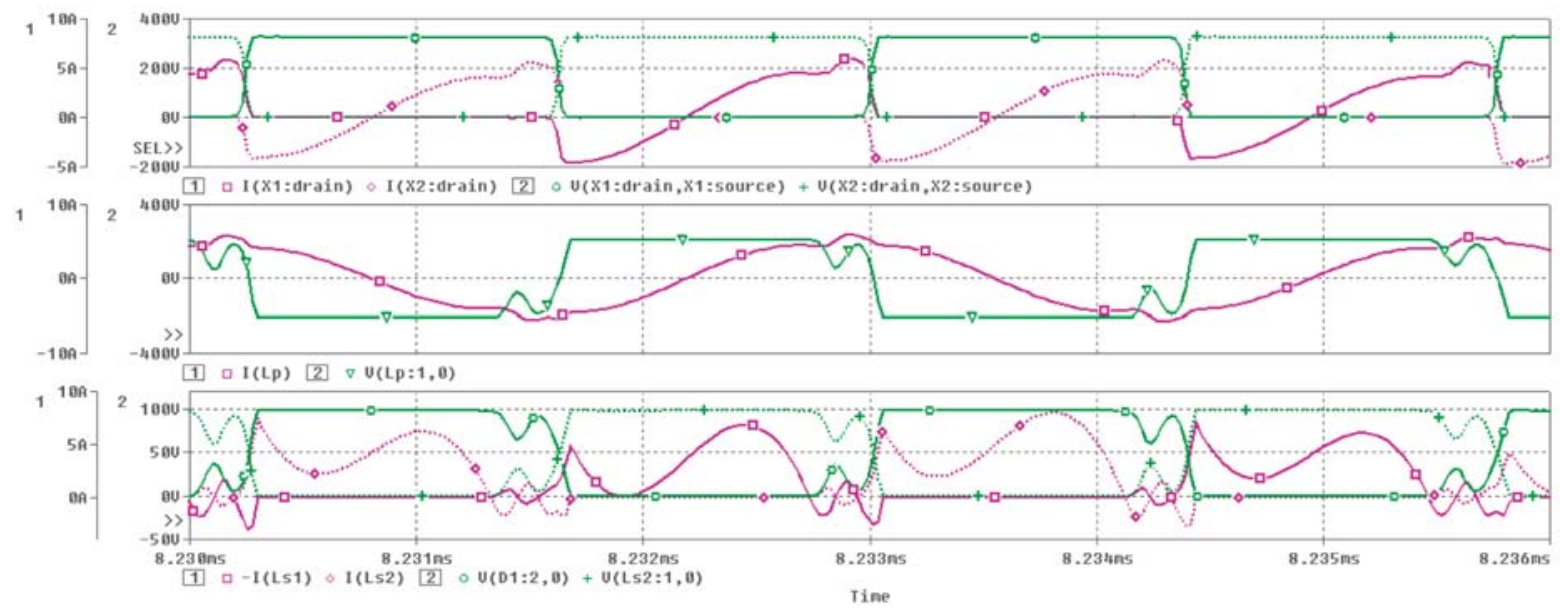

Fig. 15 Time waveforms of voltages and currents during the simulation experiment: $U_{I N}=325 \mathrm{~V}, P_{\text {OUT }}=252 \mathrm{~W}$ (from top - transistor X1a X2, transformer primary side, output diode D1 and D2)

ZCS mode. The last experiment has been done at the input voltage $U_{I N}=325 \mathrm{~V}$ and at output power $P_{\text {OUT }}=252 \mathrm{~W}$. As can be seen in this operation mode the inverter is still able to achieve ZVS conditions for the main transistors. Soft commutation with ZCS conditions are also achieved for output rectifier diodes, which are operating in discontinuous mode. After simulation experiments had been made, we made multiple graphic interpretation of converter's efficiency in dependency on converter's output power and input

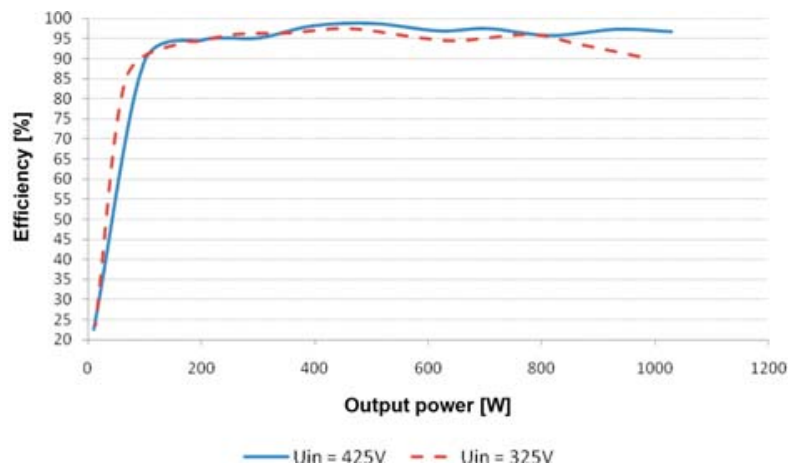

Fig. 16 Efficiency of the proposed converter in dependency on output power and input voltage $\left(U_{I N}=425 \mathrm{~V}, U_{I N}=325 \mathrm{~V}\right)$ voltage (Fig. 16). These results are good indicators of converter design and are good starting point for experimental verifications.

\section{Conclusion}

This paper describes design procedure of the LLC resonant converter. The property of converter is its ability to operate with very high switching frequency. The operation of converter at various operational modes was done through simulation analysis, which confirmed proper design of converter. In terms of design it is important to make the compromise in selection of the inductance ratio $m$. Future work will be focusing on the examination of influence of the parasitic components on the operation of LLC converter.

\section{Acknowledgement}

The authors wish to thank for the project VEGA "Research of Topology and Control of Power Electronic Supply System with Single-Phase HF Input and Two-Phase Orthogonal Output for Two-Phase SM/IM Electrical Motors". Next to grant agency APVV for project No. 20-051705 and No. APVV-0535-07. Also we would like to thank for VMSP-P-0085-09 and LPP-0366-09.

\section{References}

[1] FAIRCHILD SEMICONDUCTOR CORPORATION.: Application Note AN4151, 2007

[2] ELZBIETA SZYCHTA.: Multiresonant ZVS Switching Converters with Constant Output Voltage, Oficyna Wydawnicza Uniwersytetu Zielonogorskego 2006, ISBN 83-7481-040-8

[3] BENDA, V.: Power Semiconductors and Integrated Structures. CVUT Editor, Prague (CZ), 1994

[4] Liu R., Lee C. Q.: The LLC-type Series Resonant Converter-variable Switching Frequency Control, Proc. of the 1999 32nd Midwest Symposium of Circuits and Systems, Vol. 1, pp. 509-512

[5] DUDRIK J., DZURKO P.: Series-Parallel Resonant DC-to-DC Converter for Arc Welding, Proc. of the Conference PEMC ' 98, Prague, September 1998, Vol. 7, pp. 16-20

[6] XIAOGAO XIE, JUNMING ZHANG, CHEN ZHAO, ZHUO ZHAO, ZHAOMING QIAN: Analysis and Optimization of LLC Resonant Converter with a Novel over-current Protection Circuit, 0885-8993/07, IEEE. 